\title{
PENANGKAPAN IKAN DENGAN ALAT TANGKAP SIRINGAN (funnel trap) DI SUNGAI MUSI BAGIAN HULU, SUMATERA SELATAN
}

\author{
Syamsul Bahri'1) \\ 1) Teknisi Litkayasa pada Balai Riset Perikanan Perairan Umum, Mariana-Palembang \\ Teregristasi I tanggal: 20 April 2007; Diterima setelah perbaikan tanggal: 1 Mei 2007; \\ Disetujui terbit tanggal: 11 Mei 2007
}

\section{PENDAHULUAN}

Sumber daya ikan merupakan sumber daya hayati perairan yang dapat diperbaiki, tetapi akibat penangkapan yang tidak bertanggungjawab dapat punah. Penurunan potensi sumber daya ikan di perairan umum baik yang disebabkan oleh mortalitas alami maupun mortalitas penangkapan pada dasarnya dapat dipulihkan, namun membutuhkan waktu yang cukup lama. Untuk itu, penangkapan ikan hendak dilakukan secara rasional sehingga ketersediaan sumber daya dapat berkesinambungan.

Sungai Musi bagian hulu dimulai dari Desa Taberana, Kabupaten Rejang Lebong, Propinsi Bengkulu, dengan ketinggian $600 \mathrm{~m}$ di atas permukaan laut panjang $187 \mathrm{~km}$ berakhir di kecamatan Muara Kelingi, Kabupaten Musi Rawas Propinsi Sumatera Selatan (Samuel et al., 2002). Aktivitas penangkapan ikan dengan menggunakan alat tangkap siringan banyak dilakukan nelayan di Sungai Musi bagian hulu tepat di Desa Terusan Lama Kecamatan Tebing Tinggi Kabupaten Lahat (Lampiran 1).

Tulisan ini menyajikan informasi tentang beberapa aspek penangkapan ikan dengan menggunakan alat tangkap siringan tersebut.

\section{TEKNIK PEMBUATAN ALAT}

\section{Bahan dan Alat}

Bahan yang digunakan untuk membuat 1 unit alat tangkap siringan terdiri atas bilah bambu, kayu bulat diameter $5 / 8,8 / 12$, papan ukuran $2 / 20$ sampai dengan $2 \mathrm{~m}$, dan paku. Alat yang dipergunakan untuk pembuatan alat tangkap siringan terdiri atas gergaji, pisau, dan palu.

\section{Cara Pembuatan}

1. Bambu dibelah menjadi bilah berukuran $3 \mathrm{~cm}$ dan bagian yang tajam dibersihkan.

2. Kayu bulat 15 batang diameter $5 / 8$ sampai dengan $8 / 12$ dipotong sesuai ukuran alat tangkap yang akan dibuat.

3. Kayu bulat 10 batang diameter $5 / 8$ sampai dengan $8 / 12$ yang telah dipotong ditancapkan pada dasar sungai satu per satu dengan jarak $1 \mathrm{~m}$ dengan yang lain, disusun sesuai dengan ukuran alat tangkap yang akan dibuat. Bilah bambu dipakukan pada kerangka alat dengan jarak celah $1 \mathrm{~cm}$ satu dengan lain. Ukuran alat $50 \times 2 \times 1 \mathrm{~m}$.

4. Bagian badan alat tangkap siringan membentuk kerucut, bagian muka ada di dasar sungai semakin ke ujung semakin naik sehingga ketinggian mencapai 2 sampai dengan $3 \mathrm{~m}$ dari permukaan air.

5. Alat tangkap terdiri atas 2 bagian yaitu bagian depan disebut penetak (sapa) untuk menyatukan arus air dan bagian yang ke-2 badan alat untuk tempat ikan yang tersaring, pada mulut alat dipasang 1 keping papan ukuran 2/20 sampai dengan $2 \mathrm{~m}$ dengan kemiringan $60^{\circ}$, guna ikan yang tersaring tidak dapat keluar lagi.

\section{TEKNIK PENANGKAPAN}

Pengoperasian alat tangkap siringan sebagai berikut:

1. Alat tangkap siringan dipasang pada bagian tengah badan sungai, dengan bagian muka menghadap arus air. Aktivitas alat tangkap siringan akan berfungsi dengan baik, jika arus air deras.

2. Alat tangkap tersebut bersatu sama lain karena bilah bambu dipakukan pada kerangka alat, jarak bilah bambu satu dengan lain $1 \mathrm{~cm}$. Guna supaya alat stabil dan tidak hanyut dibawa arus air.

3. Ikan yang tersaring di lantai alat siringan diambil, diserok dengan alat tangkap sanggi dan dimasukkan pada tempat penampungan.

4. Pengoperasian alat dilakukan pada musim penghujan (air besar), sedangkan pada musim kemarau alat tangkap siringan tidak berpungsi karena arus air lamban (kecil).

\section{HASIL TANGKAPAN}

1. Hasil tangkapan nelayan berkisar antara 30 sampai dengan $50 \mathrm{~kg}$ per unit perhari.

2. Hasil tangkapan, selanjutnya ditampung dalam sangkar, yaitu alat pengumpul ikan agar ikan tetap hidup.

Berdasarkan pada hasil pengamatan dapat diketahui bahwa hasil tangkapan selama 1 bulan diperoleh 17 jenis ikan, dengan bobot $1.654 \mathrm{~kg}$. 
Beberapa jenis ikan yang dominan adalah kerali (Labocheilos sp.), meriko (Balantiocheilos lampam (Mabodes schwanefeldi), dan baung (Mystus melanopterus), cawang hidung (Schistorynchus), nemurus). Hasil tangkapan disajikan pada Tabel 1.

Tabel 1. Jumlah dan komposisi hasil tangkapan ikan dengan menggunakan alat tangkap siringan di Sungai Musi bagian hulu selama 1 bulan, bulan November 2002

\begin{tabular}{|c|c|c|c|}
\hline No. & Jenis ikan & Jumlah (kg) & Keterangan \\
\hline 1. & Baung (Mystus nemurus) & 140 & Jumlah alat tangkap 1 unit \\
\hline 2. & Baung jaksa (Macrones wicky) & 30 & \\
\hline 3. & Botia (Botia macracanthus) & 12 & \\
\hline 4. & Cawang hidung (Schistorynchus heterorhynchus) & 160 & \\
\hline 5. & Cengkak (Tor tambroides) & 112 & \\
\hline 6. & Dalum (Bagarius yerelli) & 24 & \\
\hline 7. & Kerali (Labocheilos sp.) & 300 & \\
\hline 8. & Elang (Puntius tetrazona) & 10 & \\
\hline 9. & Sebarau (Hampala macrolepidota) & 100 & \\
\hline 10. & Langli (Botia hymenophysa) & 20 & \\
\hline 11. & Lampam (Mabodes schwanefeldii) & 150 & \\
\hline 12. & Mentulu (Barbichtys laevis) & 80 & \\
\hline 13. & Meriko (Balantiocheilos melanopterus) & 240 & \\
\hline 14. & Patin (Pangasuis jambal) & 90 & \\
\hline 15. & Selimang (Crossocheilos oblongus) & 24 & \\
\hline & Sihitam (Labeo chryssophekadion) & 60 & \\
\hline \multirow[t]{2}{*}{17.} & Tilan (Mastecembulus unicolor) & 102 & \\
\hline & Jumlah & 1.654 & \\
\hline
\end{tabular}

\section{KESIMPULAN}

1. Aktivitas penangkapan ikan dengan menggunakan siringan berlangsung pada musim penghujan dipengaruhi oleh arus.

2. Hasil tangkapan siringan perbulan $1.654 \mathrm{~kg}$, terdiri atas 17 jenis ikan dan didominasi oleh Famili Cyprinidae.

\section{DAFTAR PUSTAKA}

Samuel. 2002. Inventarisasi dan distribusi biota serta karakteristik habitat perairan Sungai Musi. Laporan Teknis 2002. Proyek Penelitian Perikanan Air Tawar pada Balai Riset Perikanan Perairan Umum. Palembang. 32 hal. 
Lampiran 1. Peta lokasi penangkapan ikan dengan menggunakan siringan di bagian hulu Sungai Musi

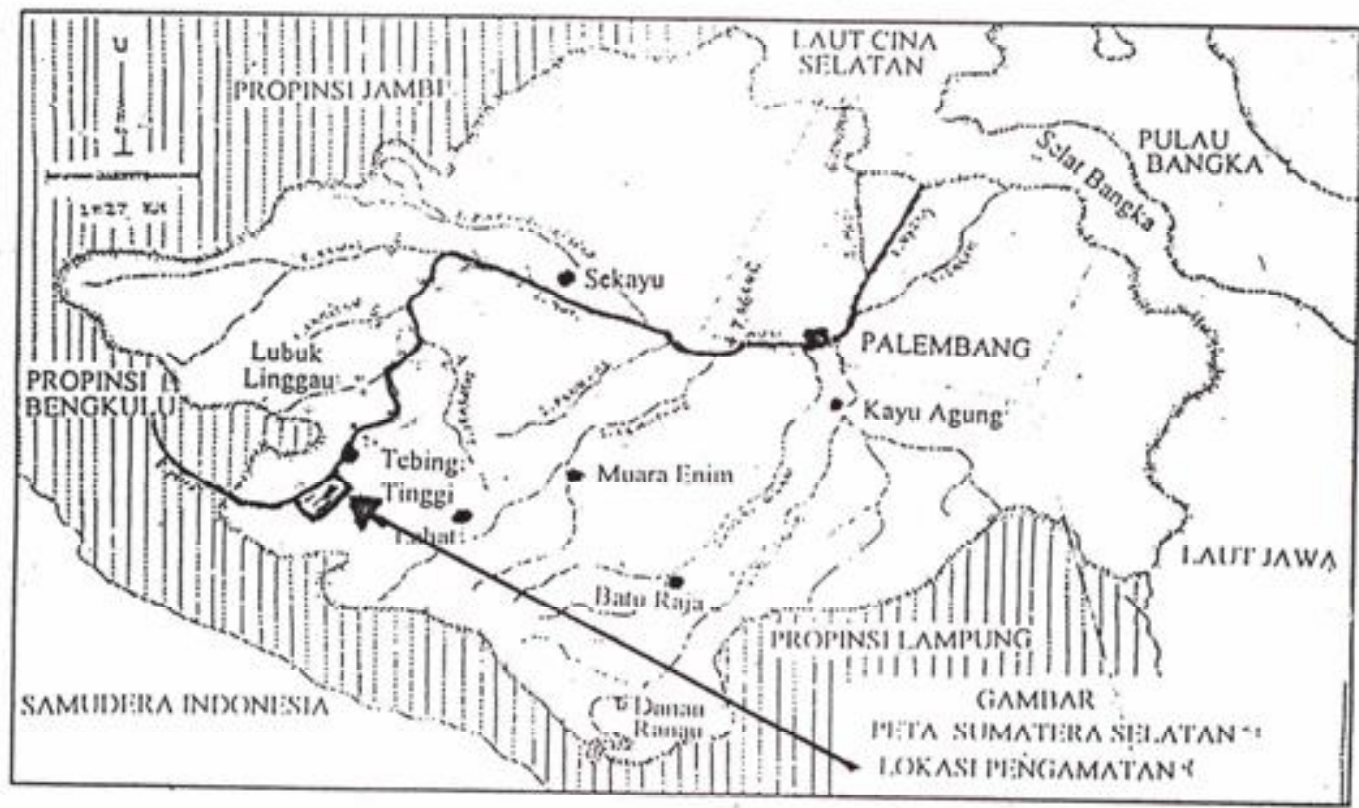

Lampiran 2. Alat tangkap siringan yang dioperasikan di bagian hulu Sungai Musi.

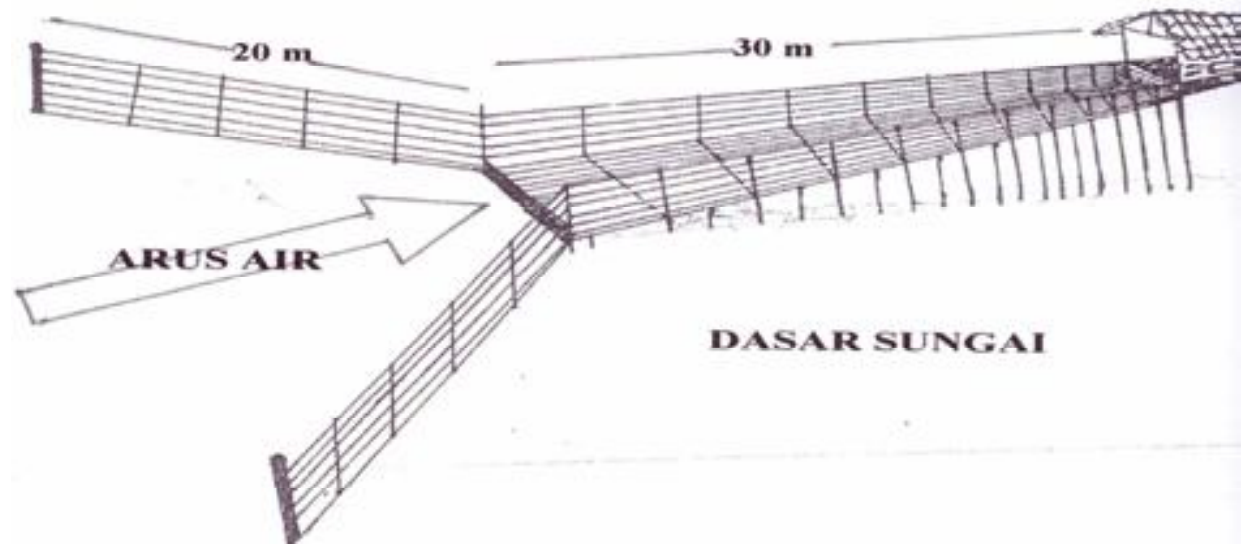

